\title{
Front Matter: Volume 8309
}

, "Front Matter: Volume 8309," Proc. SPIE 8309, Optical Transmission Systems, Subsystems, and Technologies IX, 830901 (4 January 2012); doi: 10.1117/12.923388

SPIE Event: SPIE/OSA/IEEE Asia Communications and Photonics, 2011, SPIE. Shanghai, China 


\title{
PROCEEDINGS OF SPIE
}

\section{Optical Transmission Systems, Subsystems, and Technologies IX}

\author{
Xiang Liu \\ Ernesto Ciaramella \\ Naoya Wada \\ Nan Chi \\ Editors \\ 13-16 November 2011 \\ Shanghai, China

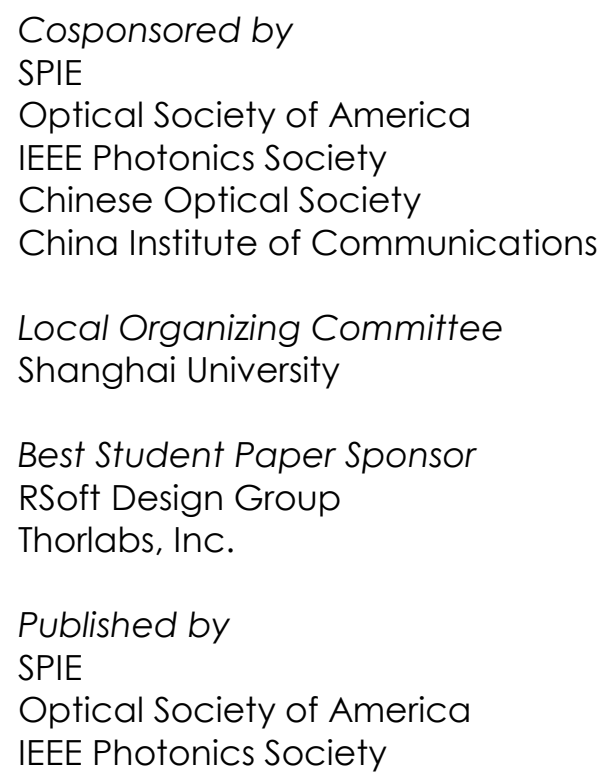


The papers included in this volume were part of the technical conference cited on the cover and title page. Papers were selected and subject to review by the editors and conference program committee. Some conference presentations may not be available for publication. The papers published in these proceedings reflect the work and thoughts of the authors and are published herein as submitted. The publisher is not responsible for the validity of the information or for any outcomes resulting from reliance thereon.

Please use the following format to cite material from this book:

Author(s), "Title of Paper," in Optical Transmission Systems, Subsystems, and Technologies IX, edited by Xiang Liu, Ernesto Ciaramella, Naoya Wada, Nan Chi, Proceedings of SPIE-OSA-IEEE Asia Communications and Photonics, SPIE Vol. 8309 (SPIE, Bellingham, WA, 2011) Article CID Number.

ISSN 0277-786X

ISBN 9780819489579

Published by

SPIE

P.O. Box 10, Bellingham, Washington 98227-0010 USA

Telephone +1 3606763290 (Pacific Time) · Fax +1 3606471445

SPIE.org

Optical Society of America

2010 Massachusetts Ave., N.W., Washington, D.C., 20036 USA

Telephone +1 2022238130 (Eastern Time) · Fax +1 2022231096

OSA.org

IEEE Photonics Society

445 Hoes Lane, Piscataway, New Jersey, 08855 USA

Telephone +1 7325628434 (Eastern Time) · Fax +1 7325628434

IEEE.org

Copyright (C) 2011, Society of Photo-Optical Instrumentation Engineers, Optical Society of America, and IEEE Photonics Society.

Copying of material in this book for internal or personal use, or for the internal or personal use of specific clients, beyond the fair use provisions granted by the U.S. Copyright Law is authorized by SPIE subject to payment of copying fees. The Transactional Reporting Service base fee for this volume is $\$ 18.00$ per article (or portion thereof), which should be paid directly to the Copyright Clearance Center (CCC), 222 Rosewood Drive, Danvers, MA 01923. Payment may also be made electronically through CCC Online at copyright.com. Other copying for republication, resale, advertising or promotion, or any form of systematic or multiple reproduction of any material in this book is prohibited except with permission in writing from the publisher. The CCC fee code is $0277-786 \times / 11 / \$ 18.00$.

Printed in the United States of America.

Publication of record for individual papers is online in the SPIE Digital Library.

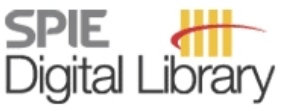

SPIEDigitalLibrary.org

Paper Numbering: Proceedings of SPIE follow an e-First publication model, with papers published first online and then in print and on CD-ROM. Papers are published as they are submitted and meet publication criteria. A unique, consistent, permanent citation identifier (CID) number is assigned to each article at the time of the first publication. Utilization of CIDs allows articles to be fully citable as soon as they are published online, and connects the same identifier to all online, print, and electronic versions of the publication. SPIE uses a six-digit CID article numbering system in which:

- The first four digits correspond to the SPIE volume number.

- The last two digits indicate publication order within the volume using a Base 36 numbering system

employing both numerals and letters. These two-number sets start with 00, 01, 02, 03, 04, 05, 06, 07, 08, 09, 0A, OB ... OZ, followed by 10-1Z, 20-2Z, etc.

The CID number appears on each page of the manuscript. The complete citation is used on the first page, and an abbreviated version on subsequent pages. Numbers in the index correspond to the last two digits of the six-digit CID number. 


\title{
Contents
}

\author{
xii Symposium Committees \\ $\mathrm{xv}$ Conference Committee \\ xix Introduction
}

\section{COMPONENT TECHNOLOGIES}

830906 A novel 2-bit photonic digital-to-analog converter based on quadrature phase modulation and differential demodulation [8309-05]

J. Liao, H. Wen, X. Zheng, B. Zhou, Tsinghua Univ. (China)

830907 Demonstration of two efficient optical 3R data regenerators at $40 \mathrm{~Gb} / \mathrm{s}$ using EAM or SOA as all-optical decision gate [8309-06]

W. Yu, X. Zhao, L. Huo, L. Wang, C. Lou, Tsinghua Univ. (China)

830908 Investigating optimal regimes of operation for pluggable XFPs in multi-channels 10G systems exploiting nonlinear effects [8309-07]

A. Atieh, Taibah Univ. (Saudi Arabia) and BTI Systems Inc. (Canada); J. P. Kemp, BTI Systems Inc. (Canada)

\section{BEST STUDENT PAPER SESSION}

830909 Wavelength and polarization division multiplexing using the $L \mathrm{P}_{11}$ mode in a two-mode fiber for mode division multiplexing [8309-08]

H. Chen, H. van den Boom, Technische Univ. Eindhoven (Netherlands); L. Grüner-Nielsen, OFS Fitel Denmark ApS (Denmark); T. Koonen, Technische Univ. Eindhoven (Netherlands)

8309 OA Closed-form expression for differential phase error variance in coherent optical systems [8309-09]

X. Chen, A. Al Amin, W. Shieh, The Univ. of Melbourne (Australia)

8309 OB Performance comparison of single carrier and OFDM in coherent optical long-haul communication systems [8309-10]

A. Lobato, Federal Armed Forces Univ. Munich (Germany); M. Kuschnerov, Nokia Siemens Networks (Germany); A. Diaz, Polytechnic Univ. of Catalonia (Spain); A. Napoli,

B. Spinnler, Nokia Siemens Networks (Germany); B. Lankl, Federal Armed Forces Univ. Munich (Germany)

8309 OC Seamless translation of optical fiber PolMux-OFDM into a 2x2 MIMO wireless transmission enabled by digital training-based fiber-wireless channel estimation (Best Student Paper) [8309-11]

X. Pang, Technical Univ. of Denmark (Denmark); Y. Zhao, Tsinghua Univ. (China); L. Deng, Huazhong Univ. of Science and Technology (China); M. B. Othman, X. YU, J. B. Jensen,

D. Zibar, I. T. Monroy, Technical Univ. of Denmark (Denmark) 
8309 OD 19-Gb/s adaptively modulated optical OFDM transmission for WDM-PON using 1 GHz RSOAs with separated I/Q baseband delivery [8309-12]

J.-M. Joo, M.-K. Hong, D. T. Pham, Yonsei Univ. (Korea, Republic of); C. J. Youn, Y.-H. Kwon,

E.-S. Nam, Electronics and Telecommunications Research Institute (Korea, Republic of);

S.-K. Han, Yonsei Univ. (Korea, Republic of)

DIGITAL SIGNAL PROCESSING I

8309 OF Optical precoding technologies with high-speed DAC at 40G or beyond (Invited Paper) [8309-14]

T. Sugihara, Mitsubishi Electric Corp. (Japan)

8309 OG Carrier phase recovery without pilot sub-carriers in coherent optical OFDM transmission systems [8309-15]

W. Liu, Q. Yang, Wuhan Research Institute of Posts and Telecommunications (China)

$8309 \mathrm{OH} \quad$ A new pilot-aided scheme to measure modulator quadrature imbalance in CO-OFDM receiver [8309-16]

L. Chen, Y. Qiao, Y. Ji, Beijing Univ. of Posts and Telecommunications (China)

8309 Ol Symbol timing synchronization algorithm for 112Gbit/s PDM CO-OFDM systems [8309-17]

Y. XU, Y. Qiao, Y. Ji, Beijing Univ. of Posts and Telecommunications (China)

8309 0J Modified $4^{\text {th }}$-power phase recovery algorithm for square-16QAM [8309-18]

Y. Fan, X. Zhang, L. Xi, W. Zhang, Beijing Univ. of Posts and Telecommunications (China)

8309 OK SPM compensation for next-generation 400-Gbps systems by means of advanced back-propagation [8309-20]

Z. Maalej, Munich Univ. of Technology (Germany); E. Timmers, V. Sleiffer, Eindhoven Univ. of Technology (Netherlands); A. Napoli, M. Kuschnerov, B. Spinnler, Nokia Siemens Networks (Germany); N. Hanik, Munich Univ. of Technology (Germany)

HIGH-SPEED TRANSMISSION

$8309 \mathrm{OL}$ What is the optimal symbol rate for long-haul transmission? (Invited Paper) [8309-21]

W. Shieh, X. Chen, A. Li, G. Gao, A. Al Amin, The Univ. of Melbourne (Australia)

\section{RADIO-OVER-FIBER AND FSO I}

$830900 \quad$ Photonic generation and wireless transmission of different pulse modulation formats for high-speed impulse radio ultrawideband over fiber systems (Invited Paper) [8309-24] S. Xie, H. Chen, M. Chen, S. Yang, P. Li, Tsinghua Univ. (China)

8309 OP Channel characteristics analysis of diffuse indoor cellular optical wireless communication systems [8309-25]

D. Wu, Z. Ghassemlooy, H. Le-Minh, S. Rajbhandari, Northumbria Univ. (United Kingdom);

L. Chao, Hong Kong Polytechinic Univ. (Hong Kong, China) 
$83090 Q$ Design and evaluation of an IDM-based MIMO FSO system over Gamma-Gamma turbulence channels [8309-26]

C. Zhang, X. Zhou, X. Zheng, J. Du, Fudan Univ. (China)

8309 OR Investigation on the generation of coherent optical multi-carriers using cascaded phase modulators [8309-28]

Y. Wang, N. Chi, J. Zhang, S. Zou, Fudan Univ. (China)

SPECIAL SYMPOSIUM: OPTICAL FIBER COMMUNICATIONS: PAST, PRESENT, AND FUTURE

8309 OT Photonics industry in China: from current status and trends to the importance of innovation (Invited Paper) [8309-30]

C. Fan, Tsinghua Univ. (China)

MODULATION, DETECTION, AND TRANSMISSION I

8309 OW Coded modulation of polarization- and space-multiplexed signals (Invited Paper) [8309-32] H. Bülow, Alcatel-Lucent Bell Labs. (Germany); Ü. Abay, A. Schenk, J. B. Huber, Univ. of Erlangen-Nuremberg (Germany)

8309 0X Advanced modulation format generation using high-speed directly modulated lasers for optical metro/access systems (Invited Paper) [8309-33]

C.-K. Chan, W. Jia, Z. Liu, The Chinese Univ. of Hong Kong (Hong Kong, China)

8309 OY Experimental demonstration of 1.45-Tb/s single channel coherent optical DFT-spread OFDM transmissions [8309-34]

Z. He, M. Luo, Z. Yang, S. Yu, Q. Yang, Wuhan Research Institute of Posts and Telecommunications (China)

$83090 Z$ Phase noise mitigation in coherent transmission system using a pilot carrier [8309-35]

T. Xu, Royal Institute of Technology (Sweden), Acreo AB (Sweden), and Tianjin Univ. (China); G. Jacobsen, Acreo AB (Sweden); S. Popov, Royal Institute of Technology (Sweden); J. Li, Acreo AB (Sweden); A. T. Friberg, Royal Institute of Technology (Sweden);

Y. Zhang, Tianjin Univ. (China)

830910 Detection diversity joint-decision MLSE to compensate chromatic dispersion impairment on optical DPSK [8309-36]

W. Ye, H. Wen, X. Zheng, Tsinghua Univ. (China)

$830911 \quad$ Non-linear compensation techniques for coherent fibre transmission [8309-37]

M. Forzati, J. Mårtensson, H.-M. Chin, M. Mussolin, Acreo AB (Sweden); D. Rafique, Tyndall National Institute, Univ. College Cork (Ireland); F. Guiomar, Instituto de Telecomunicações (Portugal)

\section{RADIO-OVER-FIBER AND FSO II}

830913 Full colorless transmission of millimeter-wave band gigabit data over WDM-PON Using sideband routing [8309-39]

Y.-Y. Won, H.-S. Kim, Y.-H. Son, S.-K. Han, Yonsei Univ. (Korea, Republic of) 
830914 Optical millimeter-wave generation utilizing optical parametric loop mirror and fiber Bragg grating [8309-41]

Y. Jiang, Guizhou Univ. (China); P. Shum, Nanyang Technological Univ. (Singapore); X. Yang, Beijing Univ. of Posts and Telecommunications (China); M. Jiang, Nanyang Technological Univ. (Singapore)

830915 A kind of DWDM-ROF system based frequency interleaving [8309-42]

X. Yang, M. Bai, X. Chen, X. Chen, Communication Univ. of China (China)

830916 10Gbit/s QAM dual multiplexing of the optical millimeter-wave generated by quadrupling the frequency of the electrical RF carrier [8309-43]

M. Zhou, J. Ma, Beijing Univ. of Posts and Telecommunications (China); Y. Shao, Fudan Univ. (China); C. Yu, X. Xin, Beijing Univ. of Posts and Telecommunications (China)

830917 40G Hz millimeter wave signal generation from 10G Hz-pulse trains modulation based on fractional Talbot effect [8309-44]

J. Guo, J. Yu, B. Wu, W. Wang, J. Luo, Tianjin Univ. (China); B. Han, Tianjin Univ. (China) and

Shanxi Datong Univ. (China); E. Yang, Tianjin Univ. (China)

SPATIAL-DIVISION MULTIPLEXING

8309 1A An optical MIMO transmission system over $80 \mathrm{~km}$ of two-mode fiber using DSP [8309-47] R. Li, W. Fang, C. Tang, N. Chi, Fudan Univ. (China)

8309 1B Design of a broadband $L_{11}$ spatial mode combiner [8309-115]

A. Li, The Univ. of Melbourne (Australia) and Ctr. for Energy-Efficient Telecommunications (CEET) (Australia); A. Al Amin, The Univ. of Melbourne (Australia); W. Shieh, The Univ. of Melbourne (Australia) and Ctr. for Energy-Efficient Telecommunications (CEET) (Australia)

\section{TRANSMISSION MODELING}

8309 1C Analysis of OFDM signal distortion in optical fiber links (Invited Paper) [8309-48]

R. Lin, Shanghai Univ. (China)

$8309 \mathrm{IF}$ Application of closed-form expressions for nonlinear transmission performance of coherent optical OFDM systems [8309-51]

G. Gao, The Univ. of Melbourne (Australia) and Beijing Univ. of Posts and

Telecommunications (China); X. Chen, The Univ. of Melbourne (Australia); W. Shieh, The Univ. of Melbourne (Australia) and Ctr. for Energy-Efficient Telecommunications (CEET) (Australia)

8309 1H Piffalls when simulating 40/100G upgrade of legacy 10G WDM transmission systems [8309-53]

H. Louchet, A. Richter, VPIsystems GmbH (Germany)

\section{MODULATION, DETECTION, AND TRANSMISSION II}

830911 Asynchronous linear optical sampling for monitoring impairments in multilevel signal modulation format generation [8309-54]

H. Wen, W. Ye, S. Nie, X. Zheng, H. Zhang, Tsinghua Univ. (China) 
8309 i Ultra-wide range in-service chromatic dispersion measurement using coherent detection and digital signal processing [8309-55]

J. Wang, Univ. of Louisiana at Lafayette (United States); X. Jiang, College of Staten Island (United States); X. He, Z. Pan, Univ. of Louisiana at Lafayette (United States)

8309 1K Analysis of modulator-induced higher-order harmonics influence on flat and stable optical comb generation based on re-circulating frequency shifter for all-optical OFDM [8309-56] L. Zhang, Y. Song, S. Zhou, Y. Li, J. Ye, R. Lin, Shanghai Univ. (China)

8309 IL D-mPSK-PolSK toward cost-effective application of polarization [8309-57]

X. Zhang, Q. Yang, Z. Yang, Wuhan Research Institute of Posts and Telecommunications (China)

$83091 \mathrm{M}$ Experimental evaluation of pilot arrangement for channel estimation in OFDM systems [8309-58]

L. Liu, X. Yang, J. Li, M. Bi, H. He, W. Hu, Shanghai Jiao Tong Univ. (China)

8309 iN Iterative phase noise estimation and suppression for CO-OFDM systems with large laser linewidth [8309-59]

C. Yang, C. He, Z. Wang, Peking Univ. (China)

\section{NETWORKING TECHNOLOGIES}

8309 IP Efficiency gain from elastic optical networks (Invited Paper) [8309-61]

A. Morea, O. Rival, Alcatel-Lucent Bell Labs. (France)

$83091 Q \quad$ The path to fully flexible optical network (Invited Paper) [8309-62]

K. Sato, Nagoya Univ. (Japan)

\section{DIGITAL SIGNAL PROCESSING II}

8309 IR FEC for high-speed optical transmission (Invited Paper) [8309-63]

C. Xie, Y. Zhao, Huawei Technologies Duesseldorf GmbH (Germany); Z. Xiao, D. Chang,

F. Yu, Huawei Technologies Co., Ltd. (China)

8309 iS High-speed transmission by direct-detection optical OFDM (Invited Paper) [8309-64]

W.-R. Peng, H. Takahashi, I. Morita, T. Tsuritani, KDDI R\&D Labs., Inc. (Japan)

\section{OPTICAL SIGNAL PROCESSING}

8309 IV Si photonics technology for future optical interconnection (Invited Paper) [8309-68]

X. Zheng, A. V. Krishnamoorthy, Oracle Labs (United States)

MODULATION, DETECTION, AND TRANSMISSION III

8309 IW All optical OFDM transmission systems (Invited Paper) [8309-69]

J.-K. K. Rhee, S.-J. Lim, M. Kserawi, KAIST (Korea, Republic of) 
8309 IY 40G transmission with spectral efficiency up to $3.2 \mathrm{bits} / \mathrm{s} / \mathrm{Hz}$ (Invited Paper) [8309-71]

D. Foursa, Tyco Electronics Subsea Communications (United States)

830912 Performance evaluation of 6-level PSK signal using differential demodulation with partial symbol delay [8309-72]

H. Y. Choi, I. Morita, KDDI R\&D Labs., Inc. (Japan)

830920 Coherent phase modulation detection for self-heterodyne phase noise measurement [8309-73]

T. N. Huynh, Dublin City Univ. (Ireland); L. Nguyen, Univ. of Nebraska-Lincoln (United States);

K. Shi, L. P. Barry, Dublin City Univ. (Ireland)

\section{ACCESS/PON TECHNOLOGIES}

830921 OFDM-PON optical fiber access technologies (Invited Paper) [8309-74]

K. Qiu, X. Yi, J. Zhang, H. Zhang, M. Deng, C. Zhang, Univ. of Electronic Science and Technology of China (China)

830922 High sensitive uplink design in WiMAX radio-over-fiber PON [8309-75]

K. Chinen, H. Mikamori, Okinawa National College of Technology (Japan)

830923 A greedy scheduling algorithm for resource assignment in OFDMA-PON [8309-76]

L. Wang, S. Xiao, M. Bi, Z. Zhou, Shanghai Jiao Tong Univ. (China)

830924 Analysis of nonlinear effects in RSOA-based OFDM-PON [8309-77]

X. Guo, R. Lin, Y. Tan, S. Zhou, J. Zhang, Shanghai Univ. (China)

830925 40Gbit/s multi-lane distribution interface converter and its application to cost-effective optical transceiver for 40G SONET/SDH signals [8309-78]

S. Aisawa, NTT Network Innovation Labs. (Japan) and Photonics Electronics Technology

Research Association (Japan); T. Ono, NTT Network Innovation Labs. (Japan); M. Tomizawa, NTT Network Innovation Labs. (Japan) and Photonics Electronics Technology Research Association (Japan)

830926 A new symbol timing synchronization scheme for direct modulation optical OFDM PON [8309-79]

M. Bi, S. Xiao, H. He, J. Li, Z. Zhou, Shanghai Jiao Tong Univ. (China)

830927 Application of nonlinear MLSE combined with FFE in 40Gbit/s Pol-Mux RZ-DQPSK optical communication system [8309-80]

M. Lin, J. Zhang, Y. Zhang, M. Zhang, Y. Huang, Beijing Univ. of Posts and

Telecommunications (China)

830928 A novel dual-polarization DQPSK system and its performance analysis [8309-81]

J. Qin, L. Xi, X. Zhang, X. XU, Beijing Univ. of Posts and Telecommunications (China) 
TELECOM POST-DEADLINE PAPERS: JOINT SESSION WITH CONFERENCES 8307, 8308, AND 8310

830929 Transmission of 1-Tb/s unique-word DFT-spread OFDM superchannel over 8,000-km SSMF [8309-120]

A. Li, The Univ. of Melbourne (Australia) and Ctr. for Energy-Efficient Telecommunications (CEET) (Australia); X. Chen, The Univ. of Melbourne (Australia); G. Gao, The Univ of

Melbourne (Australia) and Beijing Univ. of Posts and Telecommunications (China); W. Shieh, The Univ. of Melbourne (Australia) and Ctr. for Energy-Efficient Telecommunications (CEET) (Australia)

8309 2A 4x1.15-Tb/s DP-QPSK superchannel transmission over 10,181-km of EDFA amplified hybrid large-core/ultra low-loss fiber spans with 2-dB FEC margin [8309-121]

Y.-K. Huang, M.-F. Huang, D. Qian, Y. Shao, E. Ip, NEC Labs. America, Inc. (United States); T. Inove, Y. Inada, T. Ogata, Y. Aoki, NEC Corp. (Japan); T. Wang, NEC Labs. America, Inc. (United States)

\section{POSTER SESSION}

8309 2B An adaptive algorithm of fine synchronization for CO-OFDM system [8309-19]

T. Liang, Q. He, J. Yuan, L. He, Chongqing Univ. of Posts and Telecommunications (China)

8309 2C Generation of 40-GHz millimeter-wave signals based on radio-over-fiber system employing optical frequency quadrupling scheme [8309-27]

X. Guo, J. Chen, X. Chen, H. Li, L. Fu, Shanghai Univ. (China); S. Zou, Eindhoven Univ. of Technology (Netherlands)

8309 2D Performance of optical OFDM transmission over RoF system with Mach-Zehnder modulator [8309-40]

S. Zhou, Y. Song, Y. Tan, L. Zhang, Y. Li, J. Ye, R. Lin, Shanghai Univ. (China)

$83092 \mathrm{E}$ Performance improvement of secure chaotic optical communications utilizing symmetrical dispersion compensation technique [8309-82]

Q. Zhao, P. Liu, H. Yin, Dalian Univ. of Technology (China)

$83092 \mathrm{~F} \quad$ 40Gb/s all-optical binary-coded-decimal decoder [8309-83]

L. Lei, Y. Zhang, J. Dong, Y. Yu, X. Zhang, Huazhong Univ. of Science and Technology (China)

$83092 \mathrm{G}$ Transmission of $120 \mathrm{Gbit} / \mathrm{s}$ PM-DQP-ASK over $768 \mathrm{~km}$ in $10 \mathrm{Gbit} / \mathrm{s}$ NRZ-OOK WDM system [8309-84]

N. Hao, J. Zhang, X. Yuan, Y. Zhang, M. Lin, J. Tao, Beijing Univ. of Posts and

Telecommunications (China)

$83092 \mathrm{H} \quad$ Orthogonal optical label swapping and novel BER algorithm for 8PSK signal [8309-85]

C. Tang, L. Tao, R. Li, W. Fang, S. Zou, N. Chi, Fudan Univ. (China)

8309 2I A 9pJ/bit SOP optical transceiver with 80 Gbps two-way bandwidth [8309-86]

F. Liu, B. Li, Z. Li, L. Wan, W. Gao, Y. Chu, T. Du, J. Song, H. Xiang, H. Wang, K. Yang, B. Yang,

Institute of Microelectronics (China) 
8309 2J Enhancement of the laser phase noise tolerance for star 16-QAM optical coherent systems [8309-87]

J. Liu, Xi'an Univ. of Posts and Telecommunications (China); G.-K. Chang, Georgia Institute

of Technology (United States)

8309 2K A novel interpolation algorithm for pilot-assisted channel estimation in DDO-OFDM system [8309-88]

L. Liu, Shanghai Jiao Tong Univ. (China)

$83092 \mathrm{~L} \quad$ High-frequency waveform generation based on phase manipulation of optical frequency combs and square-law detection [8309-89]

G. Zhang, X. Zheng, H. Wen, H. Zhang, B. Zhou, Tsinghua Univ. (China)

8309 2M A scheme of optical 16-QAM signal generation based on Nest-SOA-MZI [8309-90]

Y. Zhan, M. Zhang, M. Liu, L. Liu, X. Chen, Beijing Univ. of Posts and Telecommunications

(China)

$83092 \mathrm{~N} \quad$ Visible light communications using blind equalization [8309-91]

B. Jin, M. Zhang, Y. Zhang, N. Hao, Beijing Univ. of Posts and Telecommunications (China)

830920 A short optical pulse source based on chirp compression and Mamyshev 2R regenerator for 200-Gbit/s OTDM System [8309-92]

Q. Wang, C. Lou, L. Huo, D. LU, H. Li, Tsinghua Univ. (China)

8309 2P A novel scheme for automatic polarization division demultiplexing [8309-93]

X. Yuan, J. Zhang, Q. Jing, Y. Zhang, M. Zhang, Beijing Univ. of Posts and

Telecommunications (China)

8309 2Q Performance of OFDM with PCF configuration in WDM-PON [8309-94]

H. Zhang, J. Zhang, M. Deng, L. Chen, K. Qiu, Univ. of Electronic Science and Technology of China (China)

8309 2R Error probability analysis in PMD-supported dual-channel optical direct detection POISK transmission systems [8309-95]

L. Wang, N. Fang, H. Cui, L. Han, Z. Huang, Shanghai Univ. (China)

830925 Performance improvement of bandwidth-flexible reconfigurable optical add/drop multiplexers with wavelength converters [8309-97]

S. You, Soochow Univ. (China)

8309 2T An application of coherent receiving system to atmospheric laser communication [8309-98] J. Tao, Y. Zhang, X. Yuan, J. Zhang, M. Zhang, Y. Huang, Beijing Univ. of Posts and Telecommunications (China)

$83092 \mathrm{U} \quad$ A practical design for compressive sampling system [8309-99]

Y. Liang, M. Chen, H. Chen, S. Xie, Tsinghua Univ. (China)

$83092 \mathrm{~V} \quad$ Mitigation of nonlinear effects in 112-Gb/s transmission at $50-\mathrm{GHz}$ channel spacing with multi-rate neighbors [8309-100]

M. Lin, Y. Zhang, J. Zhang, X. Yuan, M. Zhang, Y. Huang, Beijing Univ. of Posts and

Telecommunications (China) 
$83092 Y$ Performance comparison of phase modulated formats in $160 \mathrm{~Gb} / \mathrm{s}$ transmission system [8309-103]

D. Wang, D. Lu, C. Lou, L. Huo, W. Yu, Tsinghua Univ. (China)

$830922 \quad$ Multi-level phase-amplitude hybrid modulation and its transmission performance analysis [8309-104]

W. Fang, C. Bai, X. Zhang, Z. Zhao, W. Sun, Liaocheng Univ. (China)

830930 Photonic instantaneous microwave frequency measurement based on phase modulated links with interferometric detection assisted by a polarizer [8309-105]

D. Wang, K. Xu, J. Dai, Z. Wu, L. Gui, J. Lin, Beijing Univ. of Posts and Telecommunications (China)

830932 Probability density functions of channel estimation for MLSE in optical communications [8309-107]

L. Lu, Huazhong Univ. of Science and Technology (China) and Air Force Radar Academy (China); J. Lei, P. Ju, Y. Lei, Z. Peng, X. Zou, Huazhong Univ. of Science and Technology (China)

830933 Performance analysis of the LCoS-based switching nodes in elastic optical path network [8309-108]

Y. Zeng, N. Hua, X. Zheng, H. Zhang, B. Zhou, Tsinghua Univ. (China); Y. Xie, Institute of China Electronics Equipment System Engineering Co. (China)

830934 PMD impacts on dual-channel PolSK optical transmission system [8309-109]

H. Cui, L. Wang, N. Fang, L. Han, Z. Huang, Shanghai Univ. (China)

830935 Investigation on the upgrade of existing 10Gbps metro DWDM networks to 40 Gbps based on measured PMD data of deployed fiber in Malaysia [8309-110]

K. Khairi, Z. Lambak, A. Ahmad, M. Z. Abdul Kadir, Z. Hamzah, D. Tarsono, Z. Abd. Manaf, R. Mohamad, M. N. Abd. Rahman, N. Samsuri, K. H. Fong, TM Research \& Development Sdn. Bhd. (Malaysia)

830937 Chromatic dispersion compensation using two pilot tones in optical OFDM systems [8309-1 12]

L. Liu, X. Yang, W. Hu, Shanghai Jiao Tong Univ. (China)

830939 Error probability estimation for coherent optical PDM-QPSK communications systems [8309-116]

X. Zhu, Corning Inc. (United States); I. Roudas, Corning Inc. (United States) and Univ. of Patras (Greece); J. C. Cartledge, Queen's Univ. (Canada)

8309 3A 40-GHz radio over fiber scheme based on optical frequency multiplication with up to 1.4Gbps OFDM wireless signal employing a Mach-Zehnder modulator and no optical filtering [8309-1 17]

X. Chen, Y. Li, B. Ni, X. Guo, R. Lin, Shanghai Univ. (China)

8309 3B Numerical evaluation of engineered birefringence fiber in a 112 Gbps WDM PDM-QPSK loop setup [8309-118]

M. Mlejnek, Corning Inc. (United States); P. Sterlingov, N. Kaliteevskiy, Corning Scientific Ctr. (Russian Federation); X. Zhu, X. Chen, W. A. Wood, Corning Inc. (United States) 
8309 3C A novel synchronization scheme for free-space quantum key distribution system [8309-1 19] F. Tang, S. Gao, X. Wang, B. Zhu, Univ. of Science and Technology of China (China)

Author Index 


\title{
Symposium Committees
}

\author{
Honorary General Chairs
}

Tingye Li, AT\&T Laboratories (retired) (United States)

Bingkun Zhou, Tsinghua University (China)

General Chairs

Jian-Jun He, Zhejiang University (China)

Ken-ichi Kitayama, Osaka University (Japan)

Xingde Li, Johns Hopkins University (United States)

Technical Program Chairs

Perry Shum, Nanyang Technological University (Singapore)

Yikai Su, Shanghai Jiao Tong University (China)

Arthur Chiou, National Yang-Ming University (Taiwan, China)

Local Organizing Committee

Yunqi Liu, Shanghai University (China)

Ronghui Qu, Shanghai Institute of Optics and Fine Mechanics (China)

Tingyun Wang, Shanghai University (China)

Xiaobei Zhang, Shanghai University (China)

Steering Committee Chairs

Ming-Jun Li, Corning USA (United States)

John Zyskind, Oclaro, Inc. (United States)

Steering Committee Members

Sailing He, Zheijang University (China)

Peter Kaiser, Telcordia Technologies (retired)

Connie Chang-Hasnain, University of California, Berkeley (United States)

Chongcheng Fan, Tsinghua University (China)

Mao Qian, WRI-Fiberhome (China)

Xiaomin Ren, Bejing University of Posts \& Telecommunications (China) 
Downloaded From: https://www.spiedigitallibrary.org/conference-proceedings-of-spie on 25 Apr 2023

Terms of Use: https://www.spiedigitallibrary.org/terms-of-use 


\title{
Conference Committee
}

\author{
Conference Chair
}

Xiang Liu, Alcatel-Lucent Bell Laboratories (United States)

Cochairs

Ernesto Ciaramella, Scuola Superiore Sant'Anna (Italy)

Naoya Wada, National Institute of Information and Communications

Technology (Japan)

Nan Chi, Fudan University (China)

Program Committee

Jin-Xing Cai, Tyco Submarine Systems Ltd. (United States)

S. Chandrasekhar, Alcatel-Lucent Bell Laboratories (United States)

Magnus Karlsson, Chalmers University of Technology (Sweden)

Xinwan Li, Shanghai Jiao Tong University (China)

Junichi Nakagawa, Mitsubishi Electric Corporation (Japan)

Derek Nesset, British Telecom Research Laboratories (United Kingdom)

Richard V. Penty, University of Cambridge (United Kingdom)

Werner Rosenkranz, Christian-Albrechts-Universität zu Kiel (Germany)

William Shieh, The University of Melbourne (Australia)

Hideaki Tanaka, KDDI R\&D Laboratories, Inc. (Japan)

Hiroyuki Uenohara, Tokyo Institute of Technology (Japan)

Ting Wang, NEC Laboratories America, Inc. (United States)

Tiejun Xia, Verizon Communications (United States)

Xiangjun Xin, Beijing University of Posts and Telecommunications (China)

Lianshan Yan, Southwest Jiaotong University (China)

Qi Yang, Wuhan Research Institute of Posts and Telecommunications (China)

Changyuan Yu, National University of Singapore (Singapore)

Xiaoping Zheng, Tsinghua University (China)

Session Chairs

1A Transmission Systems

Naoya Wada, National Institute of Information and Communications Technology (Japan)

1B Component Technologies

Lianshan Yan, Southwest Jiaotong University (China) 
2A Best Student Paper Session

Ernesto Ciaramella, Scuola Superiore Sant'Anna (Italy)

2B Digital Signal Processing I

Werner Rosenkranz, Christian-Albrechts-Universität zu Kiel (Germany)

3A High-Speed Transmission

Ting Wang, NEC Laboratories America, Inc. (United States)

3B Radio-Over-Fiber and FSO I

Nan Chi, Fudan University (China)

4 Special Symposium: Optical Fiber Communications: Past, Present, and Future

Xiang Liu, Alcatel-Lucent Bell Laboratories (United States)

5A Modulation, Detection, and Transmission I

Hideaki Tanaka, KDDI R\&D Laboratories, Inc. (Japan)

5B Radio-Over-Fiber and FSO II

Xinwan Li, Shanghai Jiao Tong University (China)

6A Spatial-Division Multiplexing

William Shieh, The University of Melbourne (Australia)

6B Transmission Modeling

S. Chandrasekhar, Alcatel-Lucent Bell Laboratories (United States)

7A Modulation, Detection, and Transmission II

Xiaoping Zheng, Tsinghua University (China)

7B Networking Technologies

Kun Qiu, University of Electronic Science and Technology of China (China)

8A Digital Signal Processing II

Qi Yang, Wuhan Research Institute of Posts and Telecommunications (China)

8B Optical Signal Processing

Magnus Karlsson, Chalmers University of Technology (Sweden)

9A Modulation, Detection, and Transmission III

Junichi Nakagawa, Mitsubishi Electric Corporation (Japan)

9B Access/PON Technologies

Nan Chi, Fudan University (China) 
PD1 Telecom Post-Deadline Papers: Joint Session with Conferences 8307, 8308 , and 8310

Naoya Wada, National Institute of Information and Communications Technology (Japan) 
Downloaded From: https://www.spiedigitallibrary.org/conference-proceedings-of-spie on 25 Apr 2023

Terms of Use: https://www.spiedigitallibrary.org/terms-of-use 


\section{Introduction}

Welcome to the 2011 edition of the SPIE 8309 conference proceedings on Optical Transmission Systems, Subsystems, and Technologies. As the largest subconference within the 2011 Asia Communications and Photonics Conference (ACP' '11), our conference has been successfully held in Shanghai, China. This conference offered 30 invited presentations by world experts in this technical field, 51 oral presentations, and 30 poster presentations. The conference received 124 regular submissions, of which only $41 \%$ were accepted for oral presentation and $24 \%$ for poster presentation, indicating high paper selectivity. Conference 8309 consists of 15 regular technical sessions, covering the following technical areas:

- Optical transmission systems

- Optical components technologies

- Digital signal processing (2 sessions)

- Modulation, detection, and transmission (3 sessions)

- Spatial-division multiplexing

- Optical signal processing

- Radio-over-fiber (2 sessions)

- Access/PON technologies

- Networking technologies

There are also four special sessions, which are the highlights of the conference:

1. Special Symposium on "Optical Fiber Communications: Past, Present, and Future," dedicated to Dr. Tingye Li for his lifetime contributions to the optical communications industry and the photonics community

2. Workshop on "Spectrally Efficient and Energy-Efficient Optical Transport Systems and Subsystems," organized by Dr. S. Chandrasekhar of Bell Labs, Prof. William Shieh of University of Melbourne, and Dr. Tiejun Xia of Verizon Communications

3. Best Student Paper Competition Session, featuring 6 top ranked student papers

4. Post-deadline Paper Session, presenting the most updated research breakthroughs

In the Special Symposium, Prof. David Payne of Univ. of Southampton shared his insights on "History and future perspectives of optical fibers and amplifiers." Prof. Seb Savory of Univ. College London presented his view on "Digital coherent optical communication systems: past, present and future." Prof. Thomas Koch of 
Lehigh University provided his vision on "Photonic integration for optical fiber communications."

In the Workshop, leading world experts presented their views on how to address the pressing need to sustain the optical transmission capacity growth in a costeffective and energy-efficient manner, through the use of spectrally efficient and energy-efficient optical transport systems and subsystems.

In the Best Student Competition Session, six finalists made impressive presentations on their research works. Mr. Xiaodan Pang of Technical Univ. of Denmark was selected as the winner. Ms. Xi Chen of the Univ. of Melbourne and Ms. Adriana Patricia Lobato Polo of Univ. der Bundeswehr München were selected as the runner-ups. Congratulations to them!

In the post-deadline session, two record-breaking optical transmission results were reported. Dr. Ting Wang of NEC America presented "4x1.15-Tb/s DP-QPSK superchannel transmission over 10,181-km of EDFA amplified hybrid largecore/ultra low-loss fiber spans with 2-dB FEC margin." Mr. An Li of The Univ. of Melbourne presented "Transmission of $1-\mathrm{Tb} / \mathrm{s}$ unique-word DFT-spread OFDM superchannel over 8,000-km SSMF."

We would like to take this opportunity to thank all of our committee members for their great effort in recommending invited speakers, reviewing papers, and chairing sessions. Their strong dedication to the responsibilities of this committee is invaluable to the success of this conference.

It would be impossible to run this conference without the outstanding support of the SPIE staff members. They made our job much easier and allowed us to focus on the technical aspect of our conference.

Finally, we would like to thank all the attendees who come to give talks, present posters, and actively participate in the conference. We look forward to seeing you at future Asia Communications and Photonics Conferences! 